\title{
LA ACTIVIDAD ECONÓMICA DE LOS ASENTISTAS DE VÍVERES DE LA MARINA DE MONTEVIDEO, 1770-1810
}

\section{ECONOMIC ACTIVITY OF GROCERY ASENTISTAS OF THE MONTEVIDEO NAVY, 1770-1810}

\author{
María Emilia Sandrín* \\ Universidad Nacional de La Plata, La Plata, Argentina <mariaemiliasandrin@gmail.com>
}

Resumen. Se analiza a los asentistas de víveres de la Marina de Montevideo entre 1770 y 1810. Las múltiples actividades de los asentistas abren la puerta al mundo de la provisión de bienes y servicios, permiten mirar "desde arriba" a la sociedad y sus actores socioeconómicos, e intentan dar respuesta a diversas preguntas: ¿cuáles eran las modalidades de contrato entre los abastecedores de víveres y las autoridades de turno?, ¿qué obligaciones contraían las partes?, ¿cómo se organizaba la producción necesaria para cumplir los contratos? A su vez permiten plantear hipótesis sobre los sectores medios y bajos vinculados a esta actividad económica y sobre los posibles impactos de esta actividad en las economías locales.

Palabras clave: proveedores-asentistas; suministro de víveres; Marina; Montevideo.

Abstract. It analyzes the contractors of food Montevideo Navy between 1770 and 1810 . The multiple activities of the contractors open the door to the world of the provision of goods and services, enabling us to look "from above" society and its socio-economic actors, and try to answer several questions: what were the types of contract between food providers and the authorities in power?, and what the parties contracted obligations, how production was organized to honor the contracts required? In turn allow hypothesize about the middle and lower economic activity linked to this and the potential impacts of this activity on local economies.

Key words: suppliers-asentistas; food supply; Navy; Montevideo.

Fecha de recepción: febrero de 2013. Fecha de aceptación: mayo de 2013.

* Becaria doctoral de la Comisión Nacional de Investigaciones Científicas y Técnicas, Instituto de Investigaciones en Humanidades y Ciencias Sociales. Agradezco a los árbitros anónimos por la minuciosidad y compromiso con que hicieron las sugerencias de cambios y modificaciones para la mejora de este trabajo.

Am. Lat. Hist. Econ., año 21, núm. 1, enero-abril, 2014, pp. 92-114 


\section{INTRODUCCIÓN}

$\mathrm{D}$ iversos estudios sobre Buenos Aires y su hinterland inmediato en sus primeros años revelan que tuvo una economía próspera ${ }^{1}$ y contó con la capacidad de sostener a una importante población en tránsito. ${ }^{2}$ En el largo siglo XVIII (1680-1820) se pudo observar la progresiva constitución de un complejo portuario rioplatense con asiento en la región ${ }^{3}$ que supo satisfacer las demandas que como zona portuaria se le exigían. ${ }^{4}$ Se trata de una amplia gama de bienes y servicios necesarios para el mantenimiento de las embarcaciones que lo visitan y de sus tripulaciones, tanto durante sus estadas como para sus viajes de regreso. También generaron importantes demandas los conflictos entre castellanos y portugueses por el dominio de la región, las varias comisiones demarcadoras de límites, la guerra casi permanente con los pueblos insumisos, las expediciones de descubrimiento y conquista de las costas patagónicas e islas del Atlántico sur y el mantenimiento de los asentamientos que se generaban. En el largo siglo XVIII, el abastecimiento de bienes y servi$\operatorname{cios}^{5}$ fue un importante estímulo a la economía local, no sólo para las capas sociales altas, sino que también generó una relativa prosperidad para capas ajenas a la elite. ${ }^{6}$

La importancia de los asentistas de diversas regiones de la monarquía española ha sido señalada en unas pocas investigaciones previas, pero sin que se los analice en profundidad. Tres son los trabajos a retener; en primer lugar Torres Sánchez, quien para los reinos peninsulares ahonda en los aspectos económico-institucionales generales de esta actividad, reconoce que gracias a los asientos, los asentistas pudieron acceder a innumerables negocios extras, pero no analiza casos concretos de asentistas, con lo que se pierde la oportunidad de observar de esta

${ }^{1}$ Canabrava, Comércio, 1984; Gelman, "Économie”, 1983, "Cabildo", 1985, y "Economía”, 1987; Moutoukias, Contrabando, 1988, y Saguier, Debate, s. a.

${ }^{2}$ Gonzalez, Pequeña, 2002.

${ }^{3}$ Complejo portuario formado por Buenos Aires, Colonia del Sacramento, Montevideo, Maldonado, la Ensenada de Barragán, algunos puertos menores (como las Conchas) y un indefinido e indefinible número de desembarcaderos clandestinos, principalmente sobre la costa de Buenos Aires. Jumar, Commerce, 2002.

${ }^{4}$ Bentancur, "Actividad", 1995, "Provisión, 1996, Puerto, 1997, Puerto, 1998, y "Buenos", 2004; Jumar, Rioplatenses, 1988, Commerce, 2002; Jumar y Paredes, "Comercio", 2008; Jumar et al., “Comercio", 2006, y Sandrín, "Abasto", 2008, "Participación”, 2010, y Bizcocheras, 2011.

${ }^{5}$ Entre otras demandas se ha evidenciado el trabajo de guarda almacenes, carreteros, lancheros, peones, calafates, carpinteros, herreros, servicios fúnebres, confección y arreglos de colchones y ropa, elaboración de bizcochos, de carne salada (con toda la cadena productiva que estos generaban), entre otros bienes y servicios requeridos.

${ }^{6}$ Sandrín, Bizcocheras, 2011. 
manera las prácticas reales propias realizadas por cada individuo. ${ }^{7}$ En segundo lugar, para el espacio rioplatense Sala de Touron menciona el poderío económico de diversos asentistas y las distintas "empresas" que fueron anexando desde su función, pero tampoco investiga en detalle las prácticas concretas realizadas por los distintos individuos a cargo de los contratos. ${ }^{8}$ En tercer lugar Bentancur brinda una primera lista de los asentistas de la Marina de Montevideo, menciona su importancia económica como una de las primeras actividades generadoras de capital, realiza una caracterización general de ellos y sus operaciones, pero no ahonda en la relación entre estos y las autoridades e instituciones que controlaban estas actividades. ${ }^{9}$

En este trabajo se analiza la actividad económica de los asentistas de víveres de la Marina de Montevideo entre 1770 y 1810. A través de sus actividades se busca entrar al mundo de la provisión de bienes y servicios y tener una vista panorámica de la sociedad y sus diversos actores socioeconómicos. Se intenta también ver las modalidades y obligaciones de los contratos, las relaciones de estos individuos con las autoridades e instituciones encargadas de regularlos, la organización de la producción, el impacto de estas actividades en la economía rioplatense.

Existían varios tipos de asientos de provisión de bienes y/o servicios; aquí se analizará sólo a los asentistas de víveres de la Marina de Montevideo. ${ }^{10}$ Estos individuos no eran únicamente asentistas, esta fue una más de las actividades que económicamente desarrollaron y que dará para futuros trabajos el tratar de establecer, dentro del conjunto de estas actividades, qué lugar ocupaba la de ser asentista; si era la actividad central en torno a la cual se articulaban las demás o esta era accesoria de otras. Por ejemplo, como se verá en el texto, no se pudo establecer si algunos de los asentistas que tenían establecimientos productivos se dedicaban a la producción antes de ser asentistas, o se dedicaron luego de ganar los contratos.

Las fuentes a utilizar son contratos de asientos, cartas y notificaciones de los asentistas, recibos contables de sus negocios, legislación vigente para este tipo de transacciones, protocolos de Marina, registros

Torres, "Cuando", 2002, y "Dificultades", 2003.

${ }^{8}$ En Sala de Touron, Mostrador, 1968.

${ }^{9}$ Bentancur, "Actividad", 1995, "Provisión", 1996, Puerto, 1997, Puerto, 1998, y "Buenos", 2004.

${ }^{10}$ Archivo General de la Nación, Montevideo, Uruguay (en adelante AGNU), ex Museo Histórico Nacional, cajas 236; 240;241, carpeta 27; 256, carpeta 39, y caja 267, carpeta 50. AGNU, Protocolos de Marina, 1805-1808, y Registro de protocolizaciones, 1803-1809, fs. 39-47. 
de protocolizaciones, testamentarías, tasaciones de venta existentes en diferentes repositorios.

\section{LOS ASIENTOS DE VÍVERES}

De todos los asientos, el de la provisión de víveres fue el más importante. Los asentistas tenían una función obvia, pero fundamental: alimentar y brindar lo necesario a

las dotaciones de los bajeles de guerra, correo marítimos, guarda costas, lanchas cañoneras, embarcaciones de la carrera de Patagones y servicio de este apostadero de cualquier clase y porte que existan o entren en este puerto en destino fijo, por escala o de arribada; y generalmente a todos los individuos de la Real Armada que tengan declarado goce de ración por ordenanza, a la tropa de tierra que se embarque en los buques de su majestad o particulares cuando se armen o fleten de cuenta de la Real Hacienda para convoyes y cualesquiera otras comisiones de su real servicio, a los prisioneros de guerra y de contrabando, a los pasajeros a quienes deba suministrarse ración y a los individuos procesados y detenidos en calidad de depósito a bordo o en tierra. ${ }^{11}$

Hay que considerar que "esta provisión de víveres para las fuerzas armadas, sin duda fue el negocio al que la corona destinaba más recursos económicos". ${ }^{12}$ Baste como ejemplo que la provisión de víveres en una contienda militar podía insumir más de $50 \%$ de los gastos totales de ese conflicto. $^{13}$

Esta importante función de abastecimiento de víveres para la Marina fue primeramente realizada por los vivanderos, "esos mercaderes ambulantes dieron vida a uno de los primeros renglones locales de capital". ${ }^{14}$ Desde 1770 hasta el periodo posrevolucionario Ignacio Elía, Francisco Medina, Juan Blanco y Flaquer y Francisco Mont, abasteciendo la expedición de Cevallos; cumpliendo sucesivamente el servicio Francisco Cabrera (1780-1785), Francisco Antonio Maciel (1785-1790), Manuel Vázquez (1790-1795) y (1795-1800), Mateo Magariños (1800-1806) y José Batlle y Carreó (1806-1811).

${ }^{11}$ AGNU, ex Museo Histórico Nacional, caja 267, carpeta 50.

12 Torres, “Cuando", 2002, p. 30.

${ }^{13}$ Es el caso del Sitio a Colonia del Sacramento de 1735-1737, donde la provisión de comestibles acaparó 53.84\% del gasto total de la contienda. Véase Sandrín, Bizcocheras, 2011.

${ }^{14}$ Bentancur, Puerto, 1997, p. 198. 
En los contratos ${ }^{15}$ se estipulaban los víveres y pertrechos que componían la ración diaria de armada en puerto, ${ }^{16}$ navegando, ${ }^{17}$ de dieta, ${ }^{18}$ de viernes y sábado de Cuaresma y toda la Semana Santa. ${ }^{19}$ También se especificaban ciertas características de los alimentos "el pan [...] ha de ser de toda harina, y no de asemite u otros bodrios [...] han de comprender quatro galletas y media las dieciocho onzas", ${ }^{20}$ "la res vacuna cada 60 raciones ha de ser de novillo de tres años para arriba, sacada a lazo y muerta a cuchillo y de buena calidad [...] las que se embarquen vivas, del tamaño que pidiesen". ${ }^{21}$

La composición de las raciones que debían abastecer los asentistas de la Marina era muy similar a la ración diaria reglamentaria de los tripulantes de los navíos pertenecientes al servicio real para años anteriores ${ }^{22}$ y a las raciones brindadas a las tropas asentadas en el Río de la Plata o en tránsito hacia otros destinos. ${ }^{23}$

${ }^{15}$ Se repiten siempre las mismas cláusulas en los contratos analizados (en los primeros folios de los mismos), por lo que habría un modelo a seguir. Véase por ejemplo AGNU, ex Museo Histórico Nacional, cajas 236, f. 3, y 240, f. 1.

16 "18 onzas de vizcocho de toda arina de trigo ó 24 onzas de pan de la misma especie; 3 onzas de miniestra basta u ordinaria (habas, lentejas, chícharos y frijoles) ó dos de fina (arroz y garbanzo); una onza de sal; 1/2 onza de aji; una res de ganado bacuno para cada 60 raciones; 11/2 libra de leña seca rajada”, en AGNU, ex Museo Histórico Nacional, caja 236, f. 3.

17 " 18 onzas de vizcocho de toda arina de trigo; tres onzas de carne salada, y dos de tocino ó quatro de tocino sin carne; cinco onzas de ministra basta o $31 \frac{1}{2}$ de fina; $1 \frac{1 / 2}{2}$ onza de grasa de baca o media onza de azeyte; un celemín de sal para cada mil raciones; $1 \frac{112}{2}$ libra de leña seca rajada", en $i b i d$.

18 "12 onzas de vizcocho de arina flor; 1 quarto de gallina, y cuatro onzas de carnero, ó doze onzas de este género solo; $1 / 2$ libra de carbón, y maíz en grano o afrecho, y pasto necesario para las dietas vivas", en $i b i d$.

19 "18 onzas de vizcocho de toda arina de trigo ó 24 onzas de pan de la misma calidad; ocho onzas de corvina seca con cabeza, ó seis onzas sin ella; $1 \frac{1 / 2}{2}$ onza de grasa de baca o media onza de azeyte; una sexta parte de un quartillo de vinagre; un celemín de sal por cada mil raciones; cuatro onzas de ministra basta o $3^{1 / 2}$ de fina; $1 \frac{1}{2} 2$ libra de leña seca rajada", en $i b i d$.

${ }^{20}$ AGNU, ex Museo Histórico Nacional, caja 240, f. 1v., cláusula 8.

${ }^{21}$ AGNU, ex Museo Histórico Nacional, caja 236, f. 4, cláusula 10.

${ }^{22}$ Domingo: bizcocho, 18 onzas; vino, un cuartillo y medio; tocino, seis onzas; miniestra de garbanzos o arroz, dos onzas; leña, libra y media; agua, un azumbre; sal, un celemín para cada 1000 raciones. Lunes: bizcocho, 18 onzas; vino, un cuartillo y medio; miniestra, dos onzas; leña, libra y media; agua, un azumbre; sal, un celemín para cada 1000 raciones; carne salada, ocho onzas. Martes: íbidem en todo como el lunes. Miércoles: íbidem anterior más bacalao, cinco onzas; aceite, una onza; vinagre, $1 / 6$ de un cuartillo. Jueves: íbidem en todo como el domingo. Viernes: íbidem en todo como el miércoles. Sábado: queso, seis onzas; aceite, $1 / 2$ onza; vinagre, $1 / 6$ de un cuartillo, en Archivo General de la Nación, Buenos Aires, Argentina (en adelante AGN), IX-43-1-4, exp. 3. Para un análisis de la demanda potencial de víveres y géneros componentes de esta ración, que las tripulaciones de las embarcaciones de la navegación ultramarina generaron entre 1680 y 1778, véase Jumar et al., "Comercio", 2006.

${ }^{23}$ No he podido establecer si tenían las tropas una dieta diaria reglamentaria, he podido encontrar semejanzas en el caso del bizcocho (principal alimento de soldados y marinos), ya que les suministran 16 onzas, es decir, una libra por persona; les proveían dos onzas de yerba, dos de tabaco, sal, ají y leña. Véase Sandrín, Bizcocheras, 2011. 
Las condiciones de entrega fijada en los contratos llevaron a que algunos asentistas estructurasen su propia red de transportes. ${ }^{24} \mathrm{Si}$ por algún accidente el asentista no podía embarcar los géneros, se le permitía "su distribución y consumo en todo por diarias o ha de quedar por cuenta de la Real Hacienda en atención a los perjuicios de lo contrario". ${ }^{25} \mathrm{El}$ proveedor debía reponer en el día un género de mala calidad, de no hallarlo, el ministro podía comprarlo a cualquier costo por cuenta de él. ${ }^{26}$ Hubo asentistas que tuvieron falencias en la calidad de los víveres, uno de ellos fue Medina, a quien no se le admitieron "como raciones completas 10000 reses y ciertas cantidades de harina incluidas en su lugar", ${ }^{27}$ otro caso lo constituyó Maciel, "se le acusaba por la mala calidad de los víveres, especialmente grave en alta mar, que inclusive había motivado advertencias ministeriales". ${ }^{28}$ Concluidos los cinco años del contrato, si quedaban víveres, el asentista siguiente o la Real Hacienda se los debía pagar al asentista en curso. ${ }^{29}$

La Real Hacienda pagaría a los asentistas "cada cuatro meses, sin retrasos; de no hacerse no tendría el asentista obligación de seguir con el asiento". ${ }^{30}$ Esto no se cumplió, pues hubo reclamos por parte de los asentistas para que se les pagara lo adeudado pasado este lapso, como en el caso de Batlle, quien "jamás tuvo cumplimiento en todo el tiempo de su contrata, pasando muchos meses y aun años, para cobrar alguno". ${ }^{31}$ La Real Junta de Marina reglamentaba que "por ningún acontecimiento o motivo se podrá subir de precio la ración en los cinco años de esta contrata". ${ }^{32}$ En casos especiales, como cuando había más embarcaciones que las regulares de la Armada, se permitió aumentarlo. ${ }^{33}$

La corona, consciente de la importancia de la tarea cumplida por los asentistas, les brindó privilegios, ${ }^{34}$ como gozar del fuero de Marina ${ }^{35} \mathrm{o}$ no pagar derechos sobre los bienes que componían las raciones. ${ }^{36}$ Aun-

${ }^{24}$ Es el caso de Manuel Vázquez quien se había equipado de "carruajes, bueyes y caballos" en vistas a cumplir su contrato. Véase nota 55.

${ }_{25}$ AGNU, ex Museo Histórico Nacional, caja 236, f. 2v., cláusula 4.

${ }^{26}$ Ibid., f. 3v., cláusula 8.

${ }^{27}$ Bentancur, Puerto, 1997, p. 200.

${ }^{28}$ Ibid.

${ }^{29}$ AGNU, ex Museo Histórico Nacional, caja 236, f. 5, cláusula 14.

${ }^{30}$ Ibid., y f. 3, cláusula 6 .

${ }^{31}$ Bentancur, Puerto, 1997, p. 201.

${ }^{32}$ AGNU, ex Museo Histórico Nacional, caja 240, f. 1v., cláusula 7.

${ }^{33}$ Por ejemplo, en 1791, cuando a Vázquez le solicitan más de 77000 raciones dada la cantidad de embarcaciones que había en el puerto. Véase nota 39.

${ }^{34}$ Esta práctica también se pudo observar en España, donde los asentistas tenían privilegios en sus contratos amparados en la tradición más que en la legalidad. El fuero militar, no pagar impuestos para la compra de determinados productos y por el transporte. Torres, "Cuando", 2002.

${ }^{35}$ AGNU, ex Museo Histórico Nacional, caja 236, f. 3v., cláusula 7.

${ }^{36}$ AGNU ex Museo Histórico Nacional, caja 240, cláusula 7. 
que a inicios del siglo XIX la exención del pago de derechos fue abolida por orden real. ${ }^{37}$

Los asentistas siempre debían tener listas 20000 raciones ordinarias. ${ }^{38}$ Hubo casos excepcionales donde esta cantidad estándar se aumentó en corto tiempo. Bajo el asiento de Manuel Vázquez, en 1791, además de las 20000 raciones, la Junta de Marina le solicita 77720 raciones, correspondientes a tres meses para trece embarcaciones. ${ }^{39}$ A Mateo Magariños se le pidió que proveyera en muy poco tiempo seis buques de guerra con 157576 raciones de armada. ${ }^{40}$ En el conflictivo año 1806 se le solicitó a Batlle y Carreó que abastezca "veinte y cinco mil raciones en tiempo de paz y cincuenta mil en tiempo de guerra", ${ }^{41}$ pero "si la entrega era urgente, [tenía] un día para el apronto de cada cuatro mil raciones". ${ }^{42}$ Es decir que en 24 horas debía conseguir: 72000 onzas de bizcocho, 12000 onzas de carne salada, 20000 onzas de miniestras, además de otros víveres. ${ }^{43}$

\section{ESTRUCTURA PRODUCTIVA Y REDES}

Los asentistas debían contar con una notable estructura productiva o una red de abastecedores para poder en tan poco tiempo cumplir con la provisión de importantes números de raciones. En el caso de Batlle y Carreó

${ }^{37}$ AGNU, ex Museo Histórico Nacional, caja 267, carpeta 50.

${ }^{38}$ Dadas las elocuentes cantidades se hace necesario realizar una reflexión sobre el realismo de estas cifras. No se han encontrado quejas por desabastecimiento, reclamos o motines por hambre de las embarcaciones de la Armada. Tampoco se han hallado casos declarados de tripulación muerta en altamar por hambre. Hay que pensar que con el abastecimiento de estas raciones se está jugando la supervivencia de estas personas en el mar (un viaje a España por ejemplo duraba un promedio de 120 días) y que buena parte de la economía del Río de la Plata colonial giraba en torno al éxito del viaje de estos barcos. Seguramente algún fraude en la cantidad y la calidad hubo, pero no en cifras descomunales, pues cuando los hubo (al menos en lo concerniente a calidad) fueron denunciados, véanse los casos de Medina y Maciel, en notas 27 y 28.

${ }^{39}$ Tres fragatas, un paquebot y un bergantín que habían salido a navegar a comisión del real servicio; más una corbeta próxima a regresar a España y otra que se hallaba en las islas Malvinas; más seis bergantines del rey. Es decir que este asentista debía proveer un promedio de 863.56 raciones extras diarias. AGNU, ex Museo Histórico Nacional, caja 236, f. 7r. y 7v. Este aumento de la cantidad de raciones fue citado por Bentancur, Puerto, 1997, núm. 14, p. 222, véase también AgNu, Archivo Judicial, Protocolos de la Escribanía Pública, año 1791, t. 1, fs. 80v.-83v.

${ }^{40}$ AGNU, ex Museo Histórico Nacional, caja 267, carpeta 50. Magariños, en la "Relación de los méritos, servicios y ejercicios literarios" menciona que proveyó para estas embarcaciones una cifra mayor de 157824 raciones de armada y 6576 raciones de dieta, en AGNU, Archivos Particulares, caja 105 , carpeta 7, f. $2 \mathrm{v}$.

${ }^{41}$ AGNU, ex Museo Histórico Nacional, caja 267, carpeta 50.

${ }^{42}$ Ibid.

${ }^{43}$ Un quintal $=$ cuatro arrobas $=100$ libras $=1600$ onzas, y un quintal equivale a 45.94 kilogramos. Es decir que, calculadas con base en la ración de armada navegando (véase nota 17), el bizcocho equivale a 45 quintales, en medidas actuales, serían 2067.30 kilogramos; la carne salada suma 7.5 quintales o 344.55 kilogramos; las miniestras equivalen a 12.5 quintales o 574.25 kilogramos. 
se observa que cuando Magariños le transfiere el asiento de víveres para la Marina en $1806^{44}$ le vende también la casa de panadería y quinta La Aguada, ${ }^{45}$ establecimiento desde donde salía buena parte de los víveres necesarios para la ración. ${ }^{46}$

$\mathrm{El}$ asentista Medina también tuvo establecimiento productivo y transportes propios dedicados a la salazón de carnes en Montevideo: "la Compañía recibirá en compra y venta y se hará cargo de la Estancia del Gueli sita a la inmediación de la ciudad de Montevideo con todas sus fábricas, almacenes y demás utensilios propios para la matanza del ganado vacuno, salazón de carnes, beneficio del sebo y aprovechamiento de cueros". ${ }^{47}$ Además de dedicarse a la salazón de carnes, también lo hizo a la pesca de ballena y bacalao, a la elaboración de sebo, charque y otros derivados vacunos.

se hará cargo también [la Compañía] de toda la barriquería así como de los arpones, sangraderas, calderos, redes, instrumentos de la pesca de ballena y bacalao y toda clase de herramientas [...] tomará [...] en compra las embarcaciones maiores y menores destinadas al transporte de las carnes saladas como a la pesca de la ballena, bacalao y su conducción [...] comprará [...] las carnes saladas y embarricadas

${ }^{44}$ El traspaso del contrato de asiento de víveres se realiza por decreto del 5 de mayo de 1806 , con todas las condiciones pactadas en el remate ganado por Magariños. AGNU. Protocolos de Marina, 1805-1808, y Registro de Protocolizaciones, 1803-1809, f. 44.

${ }^{45}$ Magariños con fecha de 18 de marzo de 1806 había ganado el remate del asiento de víveres por un quinquenio pero expresa que "haviendo determinado yo Magariños pasar a España con mi familia, por convenir al sosiego de mi espíritu, y al fomento de mis intereses y sintiéndome necesario al efecto redondear, y liquidar todos los negocios de mi giro he comenzado por vender a Valle y Carreo mi casa panaderia, quinta, esclavos, elaboratorios y demas que contienen mis establecimientos de La Aguada”, en AGnu, Protocolos de Marina, 1805-1808, y Registro de Protocolizaciones, 1803-1809, f. 43v.

${ }^{46}$ Para esta tasación, véase AGNU, ex Museo Histórico Nacional, caja 174. Para la escritura, véase AGNU, Archivos Particulares, caja 106, f. 19v. Al momento de tasarlo para la venta a Batlle este establecimiento tenía 29 esclavos; de ellos, dos maestros panaderos, dos amasadores, siete peones de mano, un tahonero, dos cernidores, dos cocineros, un ayudante de batea, un aireador, un carretillero, diez quinteros. También estaban tasados para el trabajo de panadería 17 mulas, siete caballos, once sillas, almacén de la harina; cuadra de la tahonas y sus muebles: batea de amasar, tablas para poner el pan, palas bizcocheras, bancos de poner las tablas, mesa grande, tahonas, carretillas para cargar pan, "brilladoras" de brillar galleta (galleta es otra denominación del bizcocho o pan del marino), "picaderas" de picar galleta, piedras de tahonas, cueros de hornear, cueros para poner las galletas, cueros para la sal, pesa de cruz y balanza de hojalata, mortero, palas de palear trigo; cuarto del pan; dos cuartos de los cernidores; cuarto del horno. Además contaba con frutales: 90 durazneros, 207 manzanos, 29 perales, 100 parras, 19 naranjos y catorce higueras; hortalizas: canteros de cebolla, de ajos, de perejil, de alcauciles, de apio, de coliflor, de nabos, de lechugas, de arvejas, porotos y habas; varios almacenes (menciona un primero, un segundo y uno grande); velería, cocina y almacén de la velería; chanchería, cocina con su respectivo almacén; almacén de la sal; la quinta; el granero; cuarto del pajar; despensa; carpintería; entre otros bienes.

${ }^{47}$ Nota que realiza la Compañía Marítima, en Madrid, el 31 de mayo de 1790, incorporada en su testamentaría. AGNU, Escribanía de Gobierno y Hacienda, Protocolos, libro 5773, exp. 117, leg. 21 , f. 5 . 
como también el sebo puesto ya sea en barricas ya en marquetas, el charque, los cueros y quanto exista al presente beneficiado en dichas fábricas. ${ }^{48}$

Medina parece haber sido uno de esos hombres que, como sostiene Sala de Touron, "abasteciendo a Montevideo o a la Marina de Guerra y levantando saladeros, algunos entre ellos, acrecieron singularmente su fortuna" ${ }^{49}$

Esta última autora argumentaba que "los negocios que requirieron mayor inversión de capital fueron el abasto de carnes a Montevideo y el de galleta y carnes saladas a la Marina Real", ${ }^{0}$ a su vez sostenía que "el monopolio del abasto impulsó el desarrollo del saladero de Francisco Medina y algunos otros como el de Manuel Vázquez [...] y el de galleta, el del molino de La Aguada al asegurar un gran mercado permitió el montaje de las empresas más importantes de la colonia" ${ }^{51}$ Estas "empresas importantes", como se observó, en ocasiones fueron montadas por los propios asentistas para garantizarse la existencia de los víveres y/o pertrechos que compondrían las raciones que ellos debían abastecer.

Otra información importante de cómo podía ser la estructura de producción, elaboración, recolección, acopio que eran necesarios para poder cumplir con los distintos contratos la brinda el asentista Manuel Vázquez en una nota donde explica que tuvo que rebajar el precio de la ración, ya que como él estaba proveyendo de víveres a la Marina, le habían dado el asiento por todo el quinquenio de 1795-1800; "tenía muchos acopios y varios establecimientos que he preparado para continuar el asiento" ${ }^{52}$ el mismo que luego es anulado y al volverse a rematar gana nuevamente. ${ }^{53}$ Esos establecimientos que Vázquez había preparado, ciserían propios como los de los asentistas Maciel, Magariños y Batlle? El mismo Vázquez da la respuesta en otra nota a la Junta, donde explica que indefectiblemente tenía que ganar ese remate, "resuelto a quedarme con el asiento sin reparar en precio alguno" ${ }^{54}$ porque como ya tenía otorgado el asiento, "para ello pues hice acopios crecidos de los frutos y especies de ración, construyendo almacenes, formando establecimientos, equipándome de carruajes, bueyes y caballos todo a costa de mis crecidos desembolsos ${ }^{155} \mathrm{y}$, sin asiento para abastecer, toda la inversión sería inútil.

Si bien en los contratos analizados no se pudieron establecer muchos detalles acerca de la red de proveedores, cada asentista debía tenerla con-

${ }^{48}$ AGNU, Escribanía de Gobierno y Hacienda, Protocolos, libro 5773, exp. 117, leg. 21, fs. 6 y 7.

${ }^{49}$ Sala de Touron, Mostrador, 1968, p. 154.

${ }^{50}$ Ibid., p. 149.

${ }^{51}$ Ibid.

${ }^{52}$ AGNU, ex Museo Histórico Nacional, Aduana, caja 241, carpeta 27, f. 27.

${ }^{53}$ Se detalla más adelante en el trabajo este conflicto.

${ }^{54}$ Ibid., f. $29 \mathrm{v}$.

${ }^{55}$ Ibid., f. 29. 
figurada, tuviera o no establecimientos propios. ${ }^{56}$ Torres Sánchez señala que esta logística humana era el principal problema de los asentistas. ${ }^{57}$ Semejantes cascadas de contratos son esenciales para entender el sistema, pues permiten la movilización de una cadena de actores económicos hasta el nivel más bajo al servicio del contratista principal.

$\mathrm{El}$ asentista, más que un proveedor de bienes o de capitales propios, actuaba en ese contexto como proveedor de servicios de intermediación. ${ }^{58}$ Los asentistas seguramente contaron con una red mercantil fuera del espacio rioplatense que, al igual que para los hacendados-comerciantes azucareros mexicanos analizados por Ibarra y Valle,$^{59}$ incluiría una serie de engranajes vinculados con el mercado urbano: comercio interno, regional, interprovincial.

Hay que considerar que los privilegios que se otorgaban a los asentistas les permitían, como señala Torres Sánchez, poder cumplir luego con sus dependientes, ya sea de lugares próximos o lejanos. ${ }^{60}$ Ellos eran una excelente fuente de información, sabían de las cosechas, de las posibles compras, de los transportes, de los precios y disponibilidades.

Otra forma de cumplir con los asientos pactados fue el recurso a subcontratar algún rubro del mismo, si bien esta práctica no estaba permitida "impide al proveedor pueda resubastar ningún ramo de la contrata sin permiso de esta Junta" ${ }^{61}$ Un ejemplo de subcontrato fue el caso de Miguel de Zamora, quien en cuatro años del quinquenio 1790-1795 suministró el pan por contrata particular con el asentista Vázquez, no obstante la falta de granos y el crecido precio que tuvo que pagar durante tres años. ${ }^{62}$ También el asentista Maciel "contrató el suministro por cuatro años con un panadero, al que aseguró la exclusividad y le anticipó fondos para la compra de trigo". ${ }^{63}$ Un dato importante es que el bizcocho fue el único bien subcontratado, lo que sigue mostrando la importancia de este producto, pues con estas prácticas se generaban diversas jerarquías de asentistas, ya que estos subcontratistas integrarían una segunda línea de abastecimiento.

Sin contar los casos de demandas excepcionales, el asentista debía preocuparse al menos por acopiar el trigo necesario para las importantes cantidades de panificados correspondientes a las 20000 raciones que siempre debía tener listas. Según relatos del asentista Magariños en 1803, se consu-

\footnotetext{
${ }^{56}$ Para un análisis de caso sobre las redes de relaciones puestas en juego para cumplir con una demanda de abastecimiento de la Armada, véase Sandrín, Bizcocheras, 2011.

57 Torres, "Cuando", 2002.

${ }^{58}$ Dedieu, "Grupos", 2010, p. 2.

${ }^{59}$ Ibarra y Valle, "Redes", 2007.

60 Torres, "Cuando", 2002.

${ }^{61}$ AGNU, ex Museo Histórico Nacional, caja 240, f. 1, cláusula 4.

${ }^{62}$ AGNU, ex Museo Histórico Nacional, caja 241.

${ }^{63}$ Bentancur, Puerto, 1997, p. 199.
} 
mían anualmente en la provisión de víveres a los buques de la "Armadilla" entre 4500 y 5000 fanegas de trigo. ${ }^{64} \mathrm{Si}$ se tiene en cuenta que "hasta que llegaron [los Dughes, asentistas del ejército francés a España] la fanega de trigo producía 55 raciones [...] por los experimentos que hicieron con instrucción del Gobierno, hicieron ver que una fanega de trigo manejada con acierto y destreza producía 90 raciones bien acondicionadas", ${ }^{65}$ se deduce que los asentistas de víveres para la Marina Real, debían abastecer al menos entre 405000 y 450000 raciones de bizcochos por año, cantidad de por sí elocuente, pensando en las diversas esferas económicas que la cadena productiva de elaboración y comercialización de este panificado ponía en marcha. ${ }^{66}$ Sería interesante saber si existía en Buenos Aires oferta de trigo suficiente para abastecer esta demanda (hay que recordar que la mayoría del trigo usado por los asentistas para fabricar los bizcochos era comprado en Buenos Aires). Analizando los Acuerdos del Cabildo de esta ciudad se pudo establecer que continuamente se tenía la previsión para que se asegurara o se guardara el trigo necesario para el rancho de las embarcaciones y/o tropas de la Armada. ${ }^{67}$ Además, un informe del Cabildo del año 1798 menciona que se necesitaban 70000 fanegas de trigo para el consumo de la capital, 14000 más para la campaña y 12000 para la siembra en los seis pagos de esta ciudad y en las quintas; señala que "en vista de este prudente cálculo que para la mantención y siembra como para los ramos en que se invierte el trigo y la harina se necesitan 96000 fanegas, que si las 12000 de siembra rinden diez por fanega, queda de sobrante 24000 para el año próximo" ${ }^{6}{ }^{8}$

Un dato significativo de la importancia económica y política que tenía el negocio del aprovisionamiento de bizcocho - principal alimento de la ración diaria- es que tanto en Montevideo como en Buenos Aires el Cabildo recurrentemente prohibía abrir panaderías; seguramente para garantizar el negocio y la ganancia de estos asentistas y su red armada de provisión. ${ }^{69}$

${ }^{64}$ AGNU, ex Museo Histórico Nacional, caja 256, carpeta 39.

${ }^{65}$ Torres, "Dificultades", 2003, p. 773.

${ }^{66}$ El bizcocho con su completa cadena productiva y de comercialización, revela elementos poco conocidos de la estructura socioeconómica rioplatense. Para que llegase el bizcocho a bordo de los navíos o a manos de las tropas, era necesario que se pusiera en marcha todo un encadenamiento de acciones que abarcaban desde la producción de excedentes de trigo en previsión de este empleo hasta el embarque del bien; pasando por la limpieza del trigo, su molienda, acondicionamiento en sacos (después de haber fabricado los contenedores), distribución entre quienes producían el bizcocho, producirlo, acondicionarlo para el viaje y transportarlo. Véanse Sandrín, "Abasto", 2008, y Bizcocheras, 2011.

${ }^{67}$ AGN, Acuerdos del Extinguido Cabildo de Buenos Aires, serie III, t. VIII, 1930, p. 42; t. X, 1932 , p. 212, y t. XI, 1933, p. 351.

${ }^{68}$ AGN, Acuerdos del Extinguido Cabildo de Buenos Aires, serie III, t. XI, 1933, p. 351.

${ }^{69}$ Es el caso de Manuel Ximenez y Gómez, un asentista de víveres de Montevideo para los años 1812 y 1813, quien a comienzos de 1805 había arrendado la casa de panadería y atahonas de don Miguel Zamora en Montevideo, pero el Cabildo reiteradamente le prohibía abrirla. Era tal su desazón que abre una instancia judicial para que se agilicen y esclarezcan las razones por las 
Dados los grandes volúmenes de trigo que se necesitaban para hacer los panificados, la Junta reglamentó que "será de cuenta del proveedor solicitar trigo u otros géneros en la Provincia en caso de faltar en este pueblo, sin que la Junta tenga que impetrar favor alguno para ello" ${ }^{70}$ Este ítem parece que fue cumplido, al menos por el asentista Vázquez, a quien el 23 de marzo de 1796 el Cabildo de Montevideo le solicitó un préstamo de trigo, ya que los panaderos no lo tenían para abastecer de pan a la ciudad en Semana Santa, concretándose un préstamo de 100 fanegas. ${ }^{71}$

En este préstamo de trigo se pudo observar cómo se manejaba el pago de los negocios: "como es un negocio en que por una práctica inveterada, o por una razón de estado no tiene lugar el plazo, ni la fianza, sino el dinero en mano", ${ }^{72}$ y la importancia de los asentistas como acopiadores de cereal. Esta práctica no fue sólo realizada por Vázquez, también se observó en Mateo Magariños, Miguel de Zamora y José Batlle y Carreó. ${ }^{73}$

\section{REMATES EN CONFLICTO Y FAVORITISMO}

Los remates tenían postores tras varias convocatorias, iniciándose pujas que brindan datos significativos. Uno de los más interesantes fue el de 1794 , para el quinquenio $1795-1800 .^{74} \mathrm{El}$ contrato para el quinquenio 1790-1794 estuvo en manos de Manuel Vázquez. En 1794, al salir a remate el quinquenio siguiente, se desató una feroz competencia entre Vázquez por un lado y Miguel Zamora y Francisco Antonio Maciel por el otro. En la documentación se observó que Vázquez contaba con el apoyo de la Real Junta de Marina, ya que por denuncias de la otra parte se sabe que

que recurrentemente se le impide abrir esta casa panadería. Véase AGNU, Escribanía de Gobierno y Hacienda, caja 79, exp. 140. Si bien para una época anterior en el tiempo, un buen ejemplo de esta "regulación" es el lanchero Francisco Rodríguez, un transportista que en el sitio de Colonia de Sacramento de 1735-1737 realizó innumerables viajes con sus lanchas cargadas de bizcocho entre Buenos Aires y Montevideo, y que en la reunión del Cabildo del 30 de septiembre de 1738 ofrece dar el bizcocho que necesitasen las fragatas y la gente del sitio, pero esta institución no lo deja y le responde que gracias a la elaboración del bizcocho se mantenían en Buenos Aires muchos de los vecinos y viudas pobres cargados de familia. AGN, Acuerdos del Extinguido Cabildo de Buenos Aires, serie II, t. VII, 1929, pp. 501-502. Estos dos ejemplos muestran que el negocio de los bizcochos no sería tan poco rentable o mal negocio para aquel que quisiera emprenderlo. Otro dato significativo es que tanto Ximenez y Gómez como Rodríguez, conocían, por sus funciones (asentista de víveres y lanchero) las enormes cantidades de bizcocho que se producían y circulaban por ambas orillas del Río de la Plata.

${ }^{70}$ AGNU, ex Museo Histórico Nacional, caja 240, f. 1, cláusula 2.

${ }^{71}$ AGNU, Archivo General Administrativo, Libros de la Administración Central, caja 215.

${ }^{72}$ AGNU, ex Museo Histórico Nacional, caja 256, carpeta 39.

${ }^{73}$ En Sala de Touron, Mostrador, 1968, p. 148.

${ }^{74}$ AGNU, ex Museo Histórico Nacional, cajas 240 y 241, carpeta 27. 
fueron excluidos de la almoneda y no se los admitió a pujar. ${ }^{75}$ El caso llegó incluso al rey, quien les dio la razón a los denunciantes, anulándose lo actuado por la Junta y convocándose nuevamente a remate. ${ }^{76}$

En esta segunda instancia se observó que el asiento era un buen negocio y que, por esta vez al menos, la competencia entre los actores redundó en importantes beneficios económicos para la Real Hacienda. Para el quinquenio 1790-1794 Vázquez había ganado el contrato sobre la base de 31 maravedíes por ración. El remate ganado por Vázquez para el quinquenio siguiente, y anulado después, había sido por 36 maravedíes por ración. El segundo remate se inicia con una oferta de 25 maravedíes por ración y los oferentes pujan hasta llegar a 23 maravedíes cada uno, siendo finalmente preferido Vázquez porque ofrecía mejores garantías y servicios complementarios a la Real Hacienda que no fueron igualados por sus oponentes. La actitud de Vázquez de insistir para quedarse con el asiento y ganarlo por menos plata que la inicialmente propuesta y aun la que recibía por el contrato en vías de fenecer, y los argumentos esgrimidos por él para lograrlo, ${ }^{77}$ revelan que prefirió perder un poco para no perderlo todo, a la vez que se aseguraba tener la exclusividad de los abastecimientos por una década.

Una postura similar a la de Vázquez tomó Mateo Magariños cuando, siendo asentista de víveres de la Marina y por más que por una orden real del 31 de mayo de 1802 se daba curso a su petición en cuanto a que "no se obligase a este a surtir de víveres los Buques Correos, y que para su provisión se celebrara nueba contrata por subasta pública, y se le abonaran [...] las raciones que hubiese subministrado a estos correos con arreglo de la postura que se hiciese" ${ }^{78}$ se presentó al nuevo remate, compitió con Ramón de Cáceres, Francisco Antonio Maciel y Juan Ignacio Martínez y terminó quedándose, por un precio menor, con el asiento que antes había rechazado. ${ }^{79}$

Además de Vázquez, otros asentistas tuvieron vínculos y contactos con las autoridades e instituciones implicadas en las decisiones destinadas a los contratos de asientos o a los abastecimientos en sí. Es el caso de Medina con el administrador de la Aduana de Buenos Aires, Francisco

\footnotetext{
${ }^{75}$ Un dato significativo es que quienes eran dejados de lado por la Junta, no eran ajenos a los negocios de los asientos. Maciel fue asentista de víveres en el quinquenio 1785-1790, justo antes de la década de Vázquez como proveedor; asentista de velas de sebo desde 1785 hasta 1800; y también tenía el asiento del abasto de carne, yerba, sal, ají para los presos de la ciudadela y de velas de sebo para las luces de los cuarteles, guardias y destacamentos de Montevideo. En tanto Zamora había suministrado el pan en este primer quinquenio de Vázquez por medio de un subcontrato.

${ }^{76}$ AGNU, ex Museo Histórico Nacional, caja 241, carpeta 27, f. 5r. y 5v. Real Orden, Aranjuez, 8 de abril de 1795 .

${ }^{77}$ Véanse notas 53, 52, 54 y 55 donde Vázquez explica por qué rebajó el precio de la ración.

${ }^{78}$ AGNU, ex Museo Histórico Nacional, caja 241, carpeta 27, f. 25.

${ }^{79}$ Este accionar de Magariños también fue analizado por Bentancur, Puerto, 1997, nota 37, pp. 224-225.
} 
Ximenez de Mesa, quien era socio en la compañía de salazón de carnes. ${ }^{80}$ En un expediente se denuncia: "el interés oculto que versaba entre estos [Medina y su albacea Ortega] y el administrador de la Aduana añadiendo que Medina no fue el único que en esa provincia se dedicó a la salazón de carnes que ha avido y hai muchos que las benefician y que no faltarían otros que lo executasen pues toda la dificultad consiste en los auxilios; que Medina logró los de mi Real Hacienda". ${ }^{81}$

Gracias a sus contactos Medina logró préstamos para su empresa: "quince mil pesos que se le facilitaron a Medina de los caudales de la Real Aduana en virtud de providencia de la Junta Superior de Real Hacienda por via de préstamo y auxilio para el proiecto de salazón de carnes". ${ }^{82}$ Concluye la nota con una contundente expresión: "se reconoce que más bien que útil fue criminal el negociado de la salazón de carnes por este medio y la malicia de sus consocios y que aun sin estas calidades no pudiera subsistir por resultar en quiebra la testamentaria y sostenerse solo del Herario quando sin su gravamen, suplementos ni auxilios se halla fomentado este ramo en otras manos que no fijando la protección a un individuo ni estancándola podrá recibir más extenso aumento". ${ }^{83}$

\section{ABASTECIMIENTO Y DOBLE DEMANDA}

Hubo asentistas que en el momento de validez de su contrato abastecieron a la Armada Real y se dedicaron además a proveer de víveres y demás pertrechos a las tropas presentes en el Río de la Plata o en tránsito hacia otros destinos. Fue el caso de Mateo Magariños, quien

surtió de todo lo necesario á las tropas que se hallaban acampadas en sus establecimientos y fuera de ellos proporcionándoles [...] cuanto pedían, no solo á los oficiales sino a los soldados, contribuyendo diariamente á las tropas con pan fresco, leña, sal, agua, velas, verduras y carne fresca con abundancia, de modo que en su arrivo en veinte y cuatro de diciembre de mil ochocientos cinco hasta su marcha en tres de febrero de mil ochocientos seis no gastaron cosa alguna en su manutención. ${ }^{84}$

\footnotetext{
${ }^{80}$ Este dato sale a la luz cuando se produce la quiebra del administrador de dicha aduana y se da causa de ello en la testamentaría de Medina a Ortega, el albacea de este. AGNU, Escribanía de Gobierno y Hacienda, Protocolos, libro 5773, exp. 117, leg. 21, f. 14.

${ }^{81} \mathrm{Ibid}$.

${ }^{82}$ Ibid., f. 15v.

${ }^{83} \mathrm{Ibid}$., f. 16.

${ }^{84}$ AGNU, Archivos Particulares, caja 105, carpeta 7, f. 5.
} 
Estos no fueron los únicos abastecimientos a tropas que realizó Magariños, también "dispensó socorros á los cien hombres que comandaba el capitán de voluntarios de caballería de Córdoba D. Manuel de Asunsolo y Urrutia". ${ }^{85}$ Otra certificación de Soria de Santa Cruz, un coronel veterano jefe del Regimiento de voluntarios de Montevideo, con fecha de 3 de febrero de 1806 menciona que:

colocó los cuatrocientos hombres del citado regimiento, y más ciento de la frontera de Córdoba en cuadras suficientes, espaciosas y aseadas, con habitaciones independientes y decentes para todos los Oficiales que le franqueó el propietario de ellas D. Mateo Magariños, con mas toda la carne, leña, luz, agua, pan, sal y verdura, que necesitaban, y por separado mesa competente para toda la Oficialidad, y además toda la carne fresca que necesitó aquel regimiento para mil doscientos y setenta hombres que tuvo sobre las armas $[\ldots] .{ }^{86}$

[...] no sólo franqueó paños y demás géneros necesarios para ochocientas veinte y cuatro plazas del regimiento de voluntarios de Córdoba, seiscientas sesenta y siete del de Montevideo, y trescientas sesenta del cuerpo de Usares, sino también para vestir el cuerpo de Blandengues de caballería y cuanta gente se iba recolectando. ${ }^{87}$

Además, este asentista el 30 de enero de 1807 fue nombrado por el virrey "para proveer de alimentos y alojamiento á las tropas auxiliares de Buenos Aires que conducía D. Santiago Liniers" ${ }^{88}$ Este abastecimiento de dos demandas diferentes, tripulación de las embarcaciones y tropas por una misma persona, también fue observado en la primera mitad del siglo XVIII, aunque en forma distinta. En esa oportunidad el mismo proveedor abastecía del mismo bien y servicio a las tropas del Sitio a Colonia del Sacramento de 1735-1737 cuando por el conflicto bélico no salía ningún barco, es decir, cuando una demanda caía.$^{89}$ En el caso de Magariños, abastece ambas demandas pero no porque una hubiera caído, sino porque las dos fueron contemporáneas.

Varios de los asentistas, tal vez por todo lo que la corona les había brindado a partir de sus contratos y demás negocios que gracias a ellos pudieron lograr, fueron defensores del poder Real en Montevideo. Este apoyo al Real servicio se pudo ver en los préstamos dados al mismo por parte de varios de ellos; Magariños, en el año 1806 con motivo de la invasión inglesa al Río de la Plata, "puso a disposición del gobierno la suma

${ }^{85}$ Ibid.

${ }^{86}$ Ibid., f. 5v.

${ }^{87}$ Ibid., f. 7.

${ }^{88}$ Ibid., f. $7 \mathrm{v}$.

${ }^{89}$ Véase Sandrín, Bizcocheras, 2011. 
más alta del empréstito, seis mil pesos plata", ${ }^{90}$ Francisco Antonio Maciel, 2000 pesos ${ }^{91}$ también otorgó plata, aunque sin conocerse el monto, José Battle y Carreó (el asentista de Marina al momento del conflicto).$^{92}$ Otra manera de brindar el apoyo al rey fue armando la tropa y la marinería:

D. Mateo Magariños [...] á la cabeza de sus dependientes y criados se presentó en los batallones de Marina de su mando el día doce de agosto de dicho año [1810] para contener la conmoción que se experimentó con motivo de haber tomado las principales fortalezas los dos batallones que guarnecían la plaza, queriendo mutaciones con el gobierno, por cuyo motivo fue forzoso desembarcar la tropa de marina, y armar la marinería, para cuyo efecto le entregó cuarenta fusiles, diez y ocho pares de pistolas, y diez y seis sables que tenía en su fragata La Manuela, y con lo cual se armaron otros tantos hombres; cuyos servicios, así como los que suministró con sus luces en aquel día y siguientes, facilitaron los medios de apaciguar a los malcontentos. ${ }^{93}$

Enviando en 1811 víveres a España en su fragata Pastora "D. Mateo Magariños [...] entregó gratuitamente por sí, y á nombre de sus hijos, doscientas barricas con carne salada y lenguas de la más superior calidad, doscientas docenas de lenguas secas retobadas y quinientos quintales de carne tasajo". ${ }^{94}$

Llegado el momento de la revolución en Buenos Aires, Montevideo se debatía entre si debía o no unirse al accionar de la capital virreinal. Magariños en 1810 "peroró los justos motivos que mediaban para no entrar ciegamente en la absoluta unión que se opinaba por los más de los concurrentes"; ${ }^{95}$ acto por el cual este asentista "resultó sufrir [...] algunos insultos de varios particulares, tanto en público como en secreto, por sugetos de mala fe y adictos á la Capital" ${ }^{96}$ Cuando Montevideo fue ocupada por Buenos Aires en 1814, el día 15 de julio, según una certificación de don Manuel Vicente Gutiérrez, alcalde de primer voto del Ayuntamiento de Montevideo y gobernador político interino de esa ciudad, el asentista Magariños "tuvo que fugar de aquella plaza [Montevideo] dejando en ella su familia y comodidades de su casa [...] confiscándole por este hecho sus bienes y posesiones de la campaña". ${ }^{97}$ Esta fidelidad de algunos de los asentistas a su rey fue también observada por

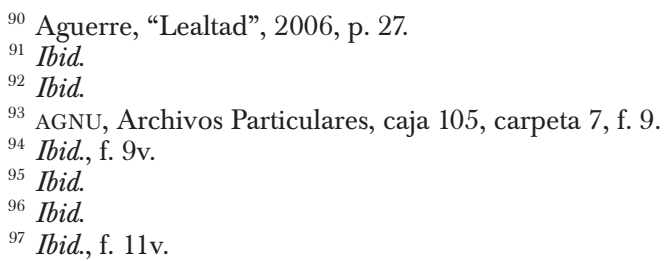


Aguerre, quien señala que "Jaime Illa, capitán de milicias y comerciante, y el Dr. Mateo Magariños Ballinas, también poderoso negociante; ambos fueron leales a su rey hasta el final"; "98 "Joanicó, Batlle y Carreó y Magariños, entre otros. Este grupo alentaba una acción política y militar de Portugal sobre el territorio oriental, con la ilusión de que los Braganza reconquistasen las provincias del Plata para Fernando VII." ${ }^{99}$

Para muchos de los asentistas rebelados, haber ganado los diversos contratos les sirvió para acceder a una infinidad de negocios y de ganancias. Esto lo tenía claro la corona pues, como argumenta Torres Sánchez, para ella "estaba fuera de duda que el asiento era una pantalla para desarrollar un sinnúmero de negocios" ${ }^{100}$ Ejemplo de esto en el Río de la Plata fueron Mateo Magariños, a quien sus paisanos de la colonia reverenciaran como el "rey chiquito" por su poder económico. ${ }^{101}$ Fue, además de asentista, abogado, comerciante, saladerista, naviero, armador de embarcaciones corsarias y prestamista, "las actividades corsarias y el abastecimiento de la Marina le proporcionaron relevantes utilidades, que reinvirtió en la producción industrial, el comercio y la actividad naviera". ${ }^{102}$ Francisco Antonio Maciel, "integrante montevideano de la elite mercantil [...] fue naviero, saladerista, procesador de sebos, traficante de esclavos, asentista, hacendado, importador y exportador". ${ }^{103}$ Fue también asentista de velas de sebo (ganó los remates de este asiento por los periodos 1790-1795 y 1795-1800). Aquí se puede ver cómo los "anexos elaboratorios" ${ }^{104}$ de esa importante empresa que fue el saladero también rindieron sus frutos en este gran mercado que era el abastecimiento de la Marina. Además, el 5 de octubre de 1798 este "múltiple actor" ganó, junto a don Eugenio Vega, por el plazo de tres años, el asiento del abasto de carne, yerba, sal, ají para "los presos de esta Real Ciudadela" 105 y de velas de sebo "para las luces de los cuarteles, guardias y destacamentos de esta plaza y su jurisdicción". ${ }^{106}$ Maciel gana nuevamente el 12 de noviembre de 1804 el mismo asiento, pero esa vez él solo. ${ }^{107}$ Por su parte, a Manuel Vázquez "ya desde el año 1773 se lo mencionaba [...] como vivandero, a la

${ }^{98}$ Aguerre, "Independencia", 2007, p. 333.

${ }^{99}$ Ibid., pp. 335-336.

${ }^{100}$ Torres, "Cuando", 2002, p. 62.

${ }^{101}$ En Sala de Touron, Mostrador, 1968, p. 149.

${ }^{102}$ Bentancur, Puerto, 1997, p. 22.

${ }^{103}$ Ibid., p. 26.

${ }^{104}$ Para ampliar esta idea véase Sala de Touron, Mostrador, 1968, p. 149.

${ }^{105}$ AGNU, Escribanía de Gobierno y Hacienda, caja 36, exp. 18, f. 1.

106 Ibid.

${ }^{107}$ AGNU, Escribanía de Gobierno y Hacienda, caja 74, exp. 164, f. 1. Primeramente este asiento se lo habían dado a José Ramírez, pero la Real Hacienda se lo interrumpe "atento el conocido perjuicio que de el resulta a la Real Hacienda comparado con el anterior que ha corrido a cargo de don Francisco Antonio Maciel” y se lo da a Maciel. AGNU, Escribanía de Gobierno y Hacienda, caja 74 , exp. 164, f. 5. 
vez que por esa misma época saló carnes para la corona, explotó sus campos, compró varios bienes raíces, se vinculó con el negocio corsario". ${ }^{108}$ Por último, José Batlle y Carreó, si bien fue "panadero, almacenero, naviero, asentista de víveres, contratista de diezmos, comerciante ultramarino", ${ }^{109}$ no tuvo la suerte de los anteriores, pues su asiento ocurrió en plena invasión inglesa al Río de la Plata, lo que le ocasionó grandes pérdidas: "apenas hecho cargo del asiento, la toma de Buenos Aires por los británicos le hizo perder 3000 fanegas de trigo ya compradas allí [...] ocupada Montevideo al año siguiente, los agresores dañaron su establecimiento de La Aguada [...] los sucesos de 1810 [...] con un bloqueo que demandó cada vez más provisiones [...] le impidió acceder por abastecimientos al mercado bonaerense". ${ }^{110}$ Batlle y Carreó, como sostiene Bentancur, "careció de fortuna en sus negocios y terminó arruinado", ${ }^{111}$ para este asentista "la oportunidad de su asiento fue tan sólo causa de enormes pérdidas". ${ }^{112}$

\section{CONCLusiones}

Los asentistas de la Marina fueron uno más de los tantos actores económico-sociales en el espacio rioplatense destinados a la satisfacción de las demandas que el complejo portuario rioplatense exigía como zona portuaria. Su función era proveer las raciones con que se mantenían las tripulaciones y guarniciones de la Armada Real en el Río de la Plata o en tránsito hacia otros destinos.

La cantidad de bienes incluidos, las complejas cadenas de producción y comercialización involucradas para que llegasen a sus consumidores, la relación que había que tener con el entramado institucional para alcanzar los contratos, convierte a estos actores en un excelente mirador para abordar diversas problemáticas relacionadas con la historia económico-social del Río de la Plata virreinal.

Sala de Touron, Bentancur y Torres Sánchez, en distintos momentos, habían mencionado la importancia de estos actores; a través de este estudio se espera haber demostrado su papel preponderante en la concreción efectiva de la dinamización que la circulación ultramarina y la corona generaban para la economía regional.

En relación con ello, en el cuerpo del texto se resaltó todo lo relacionado con la provisión del bizcocho, dado que vincula claramente la produc-

\footnotetext{
${ }^{108}$ Bentancur, Puerto, 1997, p. 18.

109 Ibid., p. 24.

${ }^{110}$ Ibid., p. 201.

111 Ibid., p. 24.

${ }^{112}$ Ibid., p. 201.
} 
ción agraria con procesos de producción, empaque y distribución. El tema del bizcocho también permitió ver la presencia de autoridades preocupadas por la calidad de la prestación de los servicios por los que pagaba, lo que sin duda traducía un interés por el bienestar de marineros y soldados. Así aparece la dimensión institucional de este rubro, y se ha mostrado que en la obtención y/o renovación de los contratos entraban en juego todos los elementos típicos de la monarquía española, favores, contrafavores, y un éxito de los actores en sus objetivos derivados de su inserción en la redes de relaciones que hacían funcionar a la monarquía. Sin embargo, también es posible pensar que la preferencia por uno u otro asentista, como en el caso de Vázquez, se relaciona con la calidad del servicio brindado.

El estímulo a la producción regional se observa claramente en la estructura productiva que debían tener los asentistas para poder en muy poco tiempo cumplir con la satisfacción del importante número de raciones solicitado. Se pudo establecer que hubo individuos que tuvieron establecimientos propios para proveerse por su cuenta de los víveres necesarios para la ración diaria reglamentaria, o al menos con buena cantidad de los víveres presentes en ellas; pero al mismo tiempo, cuando estos establecimientos no fueron suficientes para afrontar las exigencias de aprovisionamiento, los asentistas supieron contar con una densa red de proveedores para abastecerse de aquello que no podían producir. A pesar de que no estaba formalmente permitido el establecimiento de subcontratos, el importante volumen del bizcocho hizo que, en la práctica, buena parte fuera provista de esa manera. Al considerar las enormes cantidades que cada asentista debía abastecer y el trabajo que la cadena productiva y de comercialización del mismo generaba, resulta lógico que se haya subcontratado el rubro, dado que había que producir grandes cantidades en poco tiempo. Con estas prácticas de subcontratos se establecían a su vez diversas jerarquías de asentistas, ya que estos subcontratistas integrarían una segunda línea de abastecimiento. Un caso notable de estos subcontratistas fue Zamora, quien empezó proveyendo pan a través de esta práctica y terminó en forma asociada pujando por ganar un contrato de asiento de víveres.

Los asentistas, dados los grandes volúmenes de trigo que se necesitaban para hacer los panificados de los cinco años que duraba su contrato, se convertían en acopiadores de trigo, llegando en casos de escasez de granos a ser los únicos que contaban con el cereal; un ejemplo de ello es cuando ni siquiera los panaderos tenían para poder hacer el pan necesario para Semana Santa y el Cabildo recurrió al asentista Vázquez para solicitarle un préstamo de trigo. También se pudo seguir comprobando la importancia económica y política que tenía el negocio del aprovisionamiento de bizcocho pues, en Montevideo, al igual que en Buenos Aires en épocas anterio- 
res, el Cabildo recurrentemente prohibía abrir panaderías para asegurar el negocio y la ganancia de estos asentistas y su red armada de provisión.

Algunos asentistas armaron también su propia red de transporte para asegurarse el traslado de los víveres y demás géneros desde su lugar de producción, recolección o compra, hasta el muelle.

Respecto a la forma de financiación de los diversos aprovisionamientos que cada asentista debía hacer, se pudo establecer que era necesario contar con el dinero en mano para realizar los diversos acopios, pues no tenía lugar en estos negocios ni el plazo ni la fianza. Esto fue causa de pérdidas, pues, pese a que la Real Hacienda se comprometía a pagar en pocos meses sin retrasos los contratos, hubo asentistas que en varias ocasiones sufrieron la falta de pago en término; por lo tanto tampoco pudieron pagar a sus dependientes. Esto sugiere la idea de que los asentistas de por sí ocupaban un lugar prominente en la sociedad, pues tenían la capacidad de generar confianza para que se les vendiera a crédito y todos esperar el pago por parte de la Real Hacienda.

En los aspectos institucionales fue común que hubiera retrasos en la celebración de los remates de los asientos y que diversos individuos pujaran por ganarlos. En las disputas y negociaciones se pudo observar la existencia de "ayudas" o complicidades por parte de la Junta de Marina. $\mathrm{Al}$ menos en un caso el escándalo llegó a la corte, se anuló el contrato y se lo volvió a rematar, pero lo habitual parece haber sido que los conflictos, cuando los hubo, se resolvieran localmente.

Una característica recurrente de los remates fue la puja evidenciada en la rebaja en los precios estipulados originariamente en los asientos; más de un asentista prefirió perder un poco para no perderlo todo, ya que se aseguraban tener la exclusividad de los abastecimientos por largo tiempo y gozar de una serie de beneficios colaterales derivados de la función de asentista. En última instancia, para la corona era de vital importancia el aprovisionamiento, y quienes podían asegurárselo presumiblemente contarían con el favor real.

Vínculos y contactos con las autoridades e instituciones implicadas en las decisiones destinadas a los contratos de asientos o a los abastecimientos en sí, permitieron a varios asentistas sacar ventajas en sus negocios, monopolizar determinado rubro del abasto o conseguir préstamos para sus empresas. Para muchos, haber ganado los diversos contratos les sirvió para acceder a una infinidad de negocios y de ganancias. La mayoría de los "grandes asentistas" desarrollaron multiplicidad de negocios, muchos relacionados entre sí: asentistas, comerciantes, saladeristas, navieros, prestamistas, armadores de embarcaciones corsarias, y los llevaron delante de manera exitosa, salvo Batlle y Carreó, a quien la coyuntura política y económica del momento lo perjudica y termina en la ruina. 
Un problema a abordar en futuros trabajos es analizar si existió alguna relación entre el desempeño económico de los asentistas de Montevideo y su posicionamiento político respecto al proceso revolucionario de 1810 en el Río de la Plata.

Los asentistas montevideanos pudieron maximizar beneficios extendiendo sus abastecimientos a otros rubros además de la Marina pues hubo quienes, más allá de proveer a la Armada Real, abastecieron a los buques correos y se dedicaron a proveer de víveres y demás pertrechos a las tropas presentes en el Río de la Plata en el momento de validez de su contrato. Este abastecimiento de dos demandas diferentes: tripulación de la navegación ultramarina y tropas por una misma persona, también fue observado en la primera mitad del siglo XVIII, aunque de distinta manera. En esa oportunidad el mismo proveedor abastecía del mismo bien y servicio a las tropas del Sitio a Colonia del Sacramento de 1735-1737, cuando por el conflicto bélico no salía ningún barco, es decir, cuando una demanda caía. En el caso del asentista montevideano, abastece ambas demandas contemporáneas.

$\mathrm{Si}$ se incluye lo expuesto en este trabajo en una mirada que pretenda dar cuenta de las condiciones materiales de vida de los sectores medios y/o bajos de la sociedad rioplatense, se habilitan hipótesis en torno a la existencia de una relativa prosperidad en la región. Esa prosperidad provendría en buena medida del abastecimiento de bienes y/o servicios destinados a las tripulaciones de la navegación ultramarina (comercial y del real servicio) y a las tropas asentadas en el Río de la Plata o en tránsito hacia otros destinos. Todo historiador conoce los problemas que supone observar directamente los sectores sociales ajenos a la elite. Los asentistas, a través de sus contratos, redes y volúmenes de bienes provistos, permiten entrar al mundo de la producción de bienes y/o servicios y percibir, aunque de modo difuso, estos sectores sociales ajenos a la elite.

\section{FUENTES CONSULTADAS}

\section{Archivos}

AGN Archivo General de la Nación, Buenos Aires, Argentina.

AGNU Archivo General de la Nación, Montevideo, Uruguay.

\section{Bibliografia}

Aguerre Core, Fernando, "Lealtad riqueza y autonomía en el Montevideo de las invasiones inglesas", Humanidades, Universidad de Montevideo, año VI, núm. 1, 
diciembre, 2006, pp. 23-58, en <www.um.edu.uy/_...web_descarga_86_AGUE RRE_Lealtad.pdf $>$. [Consulta: agosto de 2012.]

"La independencia de América en la visión de los españoles retenidos en Montevideo (1817-1827)", Orbis Incognitivs. Avisos y Legajos del Nuevo Mundo, Universidad de Huelva, vol. 2, 2007, pp. 331-346, en <http://www.americanistas. es/biblo/textos/c12/c12-057.pdf >. [Consulta: agosto de 2012.]

Bentancur, Arturo Ariel, "La actividad corsaria montevideana (1797-1814). Una empresa económica relevante", VJornadas Interescuelas de Departamentos de Historia, Montevideo, septiembre, 1995.

"La provisión de servicios en el puerto colonial de Montevideo: alcances y limitaciones de una fuente local de riqueza", Anuario de Estudios Americanos, Escuela de Estudios Hispano-Americanos de Sevilla, vol. 53, núm. 2, 1996, pp. 123-145. El puerto colonial de Montevideo, t. I, Guerras y apertura comercial: tres lustros de crecimiento económico (1791-1803), Montevideo, Universidad de la República, 1997. El puerto colonial de Montevideo, t. II, Los años de la crisis [1807-1814], Montevideo, Universidad de la República, 1998.

"Buenos Aires y Montevideo coloniales: entre la comunidad y la controversia” en Hernán A. Silva (dir.), Los caminos del Mercosur. Historia económica regional. Etapa colonial, México, Instituto Panamericano de Geografía e Historia, 2004, pp. 427-448.

Canabrava, Alice Piffer, O comércio português no Rio da Prata, 1580-1640, Belo Horizonte, Itaiaia, 1984.

Dedieu, Jean Pierre, "Grupos financieros al servicio del rey de España. Fines del siglo XVII-principios del XVIII", HALSHS-00444581, Sciences de l'Homme et de la Société, versión 1-7, enero, 2010, en <http://halshs.archives-ouvertes.fr/halshs -00444581/> [Consulta: agosto de 2012.]

Gelman, Jorge, "Économie et Administration locale dans le Rio de la Plata du XVIIe siècle", tesis de doctorado, París, Escuela de Altos Estudios en Ciencias Sociales, 1983. "Cabildo y elite local. El caso de Buenos Aires en el siglo XVII", Revista Latinoamericana de Historia Económica y Social, Lima, núm. 6, 1985, pp. 3-20.

"Economía natural-economía monetaria: los grupos dirigentes de Buenos Aires a principios del siglo XVII", Anuario de Estudios Americanos, Escuela de Estudios Hispano-Americanos de Sevilla, núm. 44, 1987, pp. 89-107.

Gonzalez Lebrero, Rodolfo, La pequeña aldea. Sociedad y economía en Buenos Aires (1580-1640), Buenos Aires, Biblos, 2002.

Ibarra, Antonio y Guillermina del Valle PaVón, "Redes sociales e instituciones: una nueva mirada sobre viejas incógnitas", Historia Mexicana, El Colegio de México, vol. LVI, núm. 3, enero-marzo de 2007, pp. 117-723.

Jumar, Fernando, Les "rioplatenses" et le Río de la Plata. Les modalités du commerce rioplatense et les groupes locaux, 1680-1777, Mémoire du Diplôme d'Études Approfondies, París, Escuela de Altos Estudios en Ciencias Sociales, 1988. 
Le commerce atlantique au Río de la Plata, 1680-1778, Villeneuve d'Ascq, Presses Universitaires du Septentrion, 2002, 2 vols.

e ISABEl PAREDES, "El comercio intrarregional en el complejo portuario rioplatense: el contrabando visto a través de los comisos, 1693-1777", América Latina en la Historia Económica, Instituto de Investigaciones Dr. José María Luis Mora, núm. 29, enero-junio de 2008, pp. 33-99.

Jumar, Fernando, Nicolás Biangardi, José Bozzo, Sabrina Orlowski, Roberto Querzoli y María EMILIA SANDrín, "El comercio ultramarino y la economía local en el complejo portuario rioplatense. Siglo XVIII", Anuario del Instituto de Estudios Histórico-Sociales, Universidad Nacional del Centro de la Provincia de Buenos Aires, núm. XXI, 2006, pp. 235-254

Moutoukias, Zacarías, Contrabando y control colonial en el siglo XVIII. Buenos Aires, el Atlántico y el espacio peruano, Buenos Aires, Centro Editor de América Latina, [1983] 1988.

Saguier, Eduardo R., Un debate inconcluso en la América Latina (1600-2000). Cuatro siglos de lucha en el espacio colonial peruano y rioplatense y en la argentina moderna y contemporánea, en <http://www.er-saguier.org>. [Consulta: agosto de 2012.]

SALA DE Touron, Lucía, El mostrador montevideano, Uruguay, Editores Reunidos/Arca, 1968 (Enciclopedia Uruguaya, núm. 8), en 〈http://www.periodicas.edu.uy/Enciclo pedia_uruguaya/pdfs/Enciclopedia_uruguaya_08.pdf >. [Consulta: agosto de 2012.]

SANDRÍN, MARÍA EMILIA, "El abasto y la provisión de bienes y servicios en el complejo portuario rioplatense. Siglo XVIII" en Silvia C. Mallo y Beatriz I. Moreyra (coords.), Miradas sobre la historia social en la Argentina en los comienzos del siglo XXI, Córdoba, Centro de Estudios Históricos, Prof. S. A. Segreti/Universidad Nacional de La Plata, 2008, pp. 573-585.

"La participación económica de los sectores sociales bajos en la economía del complejo portuario rioplatense, en el periodo 1778 -1810 y sus posibles motivos de adhesión a la revolución”, ponencia presentada en las Jornadas Revolución, Nación y Sectores Populares en 1810, 1910 y 2010, Universidad de Quilmes, del 5 al 7 de mayo de 2010 .

Bizcocheras, lancheros y demás... Los estímulos económicos de la guerra para los sectores medios y bajos del complejo portuario rioplatense. 1735-1737, Saarbrücken, Académica Española, 2011.

Torres SÁnchez, RAFAel, "Las dificultades de ser financiero extranjero en la España de Carlos III", Actas del I Coloquio Internacional Los Extranjeros en la España Moderna, Málaga, Universidad de Málaga, 2003, t. II, pp. 771-780, ISBN 84-688-2633-2, en $<$ http://dialnet.unirioja.es/servlet/fichero_articulo?codigo=831364>. [Consulta: agosto de 2012.]

, "Cuando las reglas del juego cambian. Mercados y privilegios en el abastecimiento del ejército español en el siglo XVIII", Revista de Historia Moderna. Anales de la Universidad de Alicante, núm. 20, 2002, en <http://rua.ua.es/dspace/bitstream/10045/1414/1/RHM_20_19.pdf>. [Consulta: agosto de 2012.] 